\title{
A TECNOLOGIA DA RECICLAGEM DE POLÍMEROS
}

Márcia Aparecida da Silva Spinacé* e Marco Aurelio De Paoli

Instituto de Química, Universidade Estadual de Campinas, CP 6154, 13084-971 Campinas - SP

Recebido em 10/10/03; aceito em 18/6/04; publicado na web em 12/11/04

THE TECHNOLOGY OF POLYMER RECYCLING. Solid municipal waste contains a large volume of polymers and its final disposal is a serious environmental problem. Consequently, the recycling of the principal polymers present in the solid waste is an alternative. In this review we describe the mechanical and chemical recycling of polymers and the energy recovery from plastic wastes. Polymer recycling involves not only the development of processing technologies, but also the solution of many chemical and analytical problems. The technological, economical and social aspects of polymer recycling are also considered.

Keywords: polymer; recycling; post-consumer polymer.

\section{INTRODUÇÃO}

Os polímeros são macromoléculas caracterizadas por seu tamanho, sua estrutura química e interações intra e intermoleculares. Possuem unidades químicas que são unidas por ligações covalentes, que se repetem ao longo da cadeia. Eles podem ser naturais, como a seda, a celulose, as fibras de algodão, etc., ou sintéticos, como o polipropileno (PP), o poli(tereftalato de etileno) (PET), o polietileno (PE), o poli(cloreto de vinila) (PVC), etc. ${ }^{1-3}$. Os polímeros são classificados como termoplásticos (plásticos), termofixos, borrachas e fibras ${ }^{4}$. O termo plástico vem do grego, plastikus, que significa material adequado à moldagem. Os plásticos são materiais que, embora sólidos à temperatura ambiente em seu estado final, quando aquecidos acima da temperatura de "amolecimento" tornam-se fluidos e passíveis de serem moldados por ação isolada ou conjunta de calor e pressão ${ }^{1}$. Alguns exemplos de termoplásticos são o PP, o PE, o PET, o PVC e o poliestireno (PS). Os termoplásticos são moldáveis a quente e possuem baixa densidade, boa aparência, são isolantes térmico e elétrico, são resistentes ao impacto e possuem baixo custo, portanto, apresentam uma larga faixa de aplicações. Devido a estas propriedades o consumo dos polímeros vem crescendo no Brasil e no mundo. No Brasil em 1998 o consumo de termoplásticos era de cerca de $3 \times 10^{6} \mathrm{t}$, em 2000 foram produzidos cerca de 850 e 660 mil t de PP e de PVC; em 2002 a produção de PET, de polietileno de alta densidade (PEAD) e de PS foi cerca de 350, 800 e 314 mil t, respectivamente ${ }^{5-8}$.

Apesar da existência de uma grande variedade de termoplásticos, apenas cinco deles, ou seja, o PE, o PP, o PS, o PVC e o PET representam cerca de $90 \%$ do consumo nacional. Dentre estes termoplásticos o PET apresenta um dos maiores índices de crescimento em consumo no País, acima de $2.200 \%$ na última década ${ }^{9}$. No Brasil, em 1997, os principais termoplásticos foram utilizados em embalagens primárias $(31 \%)$, descartáveis $(22 \%)$, construção civil (14\%), outros materiais $(13 \%)$, produtos ao consumidor $(6 \%)$, filmes $(5 \%)$, eletrodomésticos $(5 \%)$, fibras $(3 \%)$ e setor automotivo $(1 \%)^{10}$.

Segundo levantamentos feitos em grandes cidades brasileiras, os principais polímeros encontrados nos resíduos sólidos urbanos são o polietileno de alta e baixa densidade (PEAD e PEBD), o PET, o PVC e o PP. Outros tipos de polímeros encontrados correspondem a apenas $11 \%$ do total $^{4}$ (Figura 1).

*e-mail: marcias@iqm.unicamp.br

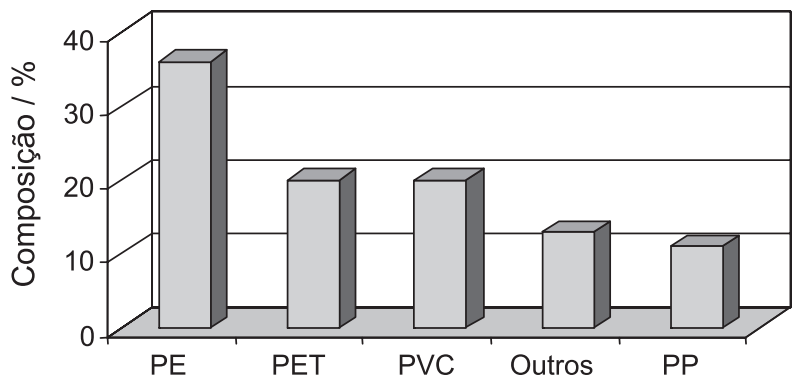

Figura 1. Termoplásticos mais encontrados no resíduo sólido urbano brasileiro

De modo geral, as indústrias que estão mais interessadas em reciclar seus resíduos poliméricos são dos segmentos de embalagens e automotivo ${ }^{11}$. A energia gasta para o transporte é consideravelmente reduzida ao substituir embalagens de vidro por polímero. Por exemplo, um caminhão carregado de água mineral engarrafada em vidro está, na verdade, transportando $57 \%$ em massa $(\mathrm{m} / \mathrm{m})$ de água e $43 \%$ $\mathrm{m} / \mathrm{m}$ de vidro ${ }^{12-14}$. Em 2000 no Brasil, cerca de 15 e $26 \%$ dos produtos foram embalados por termoplásticos rígidos e flexíveis, respectivamente. Nos EUA estes valores foram de 21 e $9 \%{ }^{15}$.

Em 2002 a Datamark ${ }^{15}$ divulgou dados da evolução do volume $\left(10^{3} \mathrm{t}\right)$ e da taxa de crescimento (em milhões de US\$) dos seguintes termoplásticos: PEBD, PEAD, PS, PVC, PP e PET, que foram utilizados no Brasil para produção de embalagens no período de 1982 a 2002. Estes dados mostraram que o PEAD (\% volume de 929 e \% valor de crescimento de 1304) e o PP (\% volume de 464 e \% valor de crescimento de 448) apresentaram um aumento significativo de volume e da taxa de crescimento, comparado ao PVC que apresentou uma diminuição nestes valores (\% volume de -21 e \% valor de crescimento de - 8). O PEBD (\% volume de 36 e $\%$ valor de crescimento de 43) e o PS (\% volume de 120 e \% valor de crescimento de 152) apresentaram um aumento menos significativo. Não é possível fazer uma comparação do PET, pois ele só foi citado a partir de 2002. No entanto, ele apresentou dados de volume e valor comparáveis ao PEAD.

Os polímeros mais reciclados após o uso neste setor são embalagens de PET, de PVC, de PP e de PE, engradados de PEAD e filmes de PE, PP, PVC e PET ${ }^{16}$. 


\section{RECICLAGEM DE POLÍMEROS}

Em 1996 foi estimado que a reciclagem de polímeros no Brasil crescia em média $15 \%$ ao ano desde o início da década ${ }^{17}$. Em 2000, a Plastivida (marca registrada de propriedade da ABIQUIM, Associação Brasileira da Indústria Química) estimou um índice médio de reciclagem em torno de $17,5 \%$. As pesquisas mostraram as taxas de reciclagem de polímeros na Grande São Paulo, Bahia, Ceará, Rio de Janeiro e no Rio Grande do Sul que apresentou a maior taxa, de $27,6 \%{ }^{8}$. O PE e o PP são os polímeros reciclados por um maior número de empresas recicladoras, e cerca da metade destas empresas reciclam de 20 até 50 t/mês, poucos superam a faixa de 100 t/mês. Entre as principais aplicações dos polímeros reciclados estão as utilidades domésticas. Os preços dos polímeros pós-consumo para reciclagem variam dependendo da oferta por região, das condições (sujo ou limpo, solto ou enfardado) e da origem (sucateiros, coleta seletiva, catadores, unidades de triagem). Embora muitos recicladores comercializem polímero reciclado na forma de granulado, a maioria deles transformam o polímero até obtenção do produto final ${ }^{18}$.

Dentre os polímeros reciclados, o PET destaca-se pelo alto índice de reciclagem atingido em um curto período de existência ${ }^{19}$. No início dos anos 80 os EUA e o Canadá reciclavam o PET para fazer enchimento de almofadas, posteriormente, com a melhora na qualidade do PET reciclado, surgiram aplicações importantes, como tecidos e recipientes para produtos não alimentícios. Na década de 90 o governo americano autorizou o uso do material reciclado em embalagens multicamadas para alimentos onde o material reciclado não tem contato com o alimento, pois fica na camada intermediária ${ }^{20}$. Atualmente, nos EUA e em alguns países da Europa é permitida a utilização de PET reciclado para a confecção de embalagens monocamadas que têm contato direto com alimentos. Para este fim foram desenvolvidas tecnologias conhecidas como "bottle-to-bottle" que envolvem etapas de lavagem, descontaminação, cristalização, pós-condensação no estado sólido e extrusão do PET. Alguns dos processos patenteados são o supercleaning ${ }^{\mathrm{TM}}$, Hybrid UnPET ${ }^{\mathrm{TM}}$, Supercycle ${ }^{\mathrm{TM}}$ Erema $^{\mathrm{TM}}$ entre outros ${ }^{21-24}$.

No Brasil, de acordo com a portaria n ${ }^{\circ} 987$ de 1998 da Secretaria de Vigilância Sanitária do Ministério da Saúde, apenas é possível a utilização de PET pós-consumo em embalagens multicamadas destinadas ao acondicionamento de bebidas carbonatadas não alcoóli$\operatorname{cas}^{25}$. Portanto, os artefatos fabricados de polímeros reciclados têm limitações de aplicação, ou seja, não podem ser utilizados em contato com bebidas, remédios, alimentos, brinquedos e material de uso hospitalar pois, dependendo do uso anterior, ele pode estar contaminado ${ }^{26,27}$. Então, o PET reciclado é utilizado como fibra têxtil (41\%), mantas de não tecido (16\%), cordas (15\%), resinas insaturadas (10\%), embalagens $(9 \%)$, cerdas de vassouras e escovas $(5 \%)$ e de outros produtos $(4 \%)^{28,29}$.

Visando reduzir o descarte dos polímeros reciclados é conveniente que estes sejam utilizados em aplicações de longa vida útil, como pavimentação, madeira plástica, construção civil, plasticultura, indústria automobilística e eletroeletrônica, etc.

\section{METODOLOGIAS DE RECICLAGEM DE POLÍMEROS}

A reciclagem de polímeros pode ser classificada em quatro categorias: primária, secundária, terciária e quaternária ${ }^{26,30}$.

Reciclagem primária: consiste na conversão dos resíduos poliméricos industriais por métodos de processamento padrão em produtos com características equivalentes àquelas dos produtos originais produzidos com polímeros virgens; por exemplo, aparas que são novamente introduzidas no processamento.

Reciclagem secundária: conversão dos resíduos poliméricos provenientes dos resíduos sólidos urbanos por um processo ou uma combinação de processos em produtos que tenham menor exigência do que o produto obtido com polímero virgem, por exemplo, reciclagem de embalagens de PP para obtenção de sacos de lixo.

Reciclagem terciária: processo tecnológico de produção de insumos químicos ou combustíveis a partir de resíduos poliméricos.

Reciclagem quaternária: processo tecnológico de recuperação de energia de resíduos poliméricos por incineração controlada.

A reciclagem primária e a secundária são conhecidas como reciclagem mecânica ou física, o que diferencia uma da outra é que na primária utiliza-se polímero pós-industrial e na secundária, pósconsumo. A reciclagem terciária também é chamada de química e a quaternária de energética.

\section{Reciclagem mecânica}

A reciclagem mecânica pode ser viabilizada através do reprocessamento por extrusão, injeção, termoformagem, moldagem por compressão, etc. Para este fim são necessários alguns procedimentos que incluem as seguintes etapas: 1) separação do resíduo polimérico, 2) moagem, 3) lavagem, 4) secagem, 5) reprocessamento e, finalmente, a transformação do polímero em produto acabado. Existem variações nestas etapas devido à procedência e o tipo de polímero, além das diferenças de investimentos e equipamentos utilizados nas plantas de processamento ${ }^{31}$. Não existem muitos detalhes sobre os processos industriais devido ao interesse econômico das indústrias que atuam neste setor, que normalmente protegem seus procedimentos por patentes ${ }^{32,33}$. Os esforços atuais estão direcionados no sentido de se obter um produto acabado obtido de polímero reciclado que possua propriedades o mais próximas possíveis do polímero virgem, para serem empregados na confecção de materiais com aplicações mais nobres.

A etapa de separação é importante, pois através dela é necessário limitar as impurezas a níveis inferiores a $1 \% \mathrm{~m} / \mathrm{m}$. A presença de macrocontaminantes, como vidro, papel, metal ou outros polímeros, mesmo em concentrações pequenas pode alterar as propriedades do polímero $^{34}$. Dependendo da forma de coleta, das necessidades do mercado ou do custo de mão-de-obra, a separação dos polímeros pode ser manual ou automatizada. A identificação dos polímeros é uma medida importante para facilitar a separação dos mesmos e pode ser utilizada por todos os ramos da indústria de reciclagem de polímeros $^{29}$.

No Brasil como a maioria das empresas de reciclagem é de pequeno porte e a mão-de-obra é barata, a separação é feita principalmente de forma manual. A separação dos polímeros pode ser feita através da identificação da simbologia contida no produto acabado ${ }^{35}$ (Figura 2) e/ou a utilização de testes simples, como o de odor dos vapores de queima, aparência da chama, temperatura de fusão e solubilidade, os quais são baseados em suas características físicas e de degradação térmica, que são distintas ${ }^{5,36,37}$. Além disto, os polímeros são utilizados para fabricação de diversos produtos acabados; no entanto, alguns deles só podem ser produzidos a partir de um tipo específico de polímero, como as embalagens de bebidas carbonatadas que são fabricadas de PET, facilitando assim sua identificação e separação do resíduo polimérico ${ }^{37}$.

De modo geral as empresas de reciclagem de polímeros fazem a separação por diferença de densidade ${ }^{36}$. O esquema da Figura 3 mostra como é possível fazer a separação dos resíduos poliméricos misturados através da diferença de densidade, utilizando tanques com água e/ou soluções alcoólicas ou salinas.

A separação automatizada baseada na diferença de densidade é muito utilizada para o PE, o PP, o PS, o PVC e o PET e é realizada em tanques de flotação $0^{30,38-41}$ ou hidrociclones ${ }^{38,42}$. Quando dois 


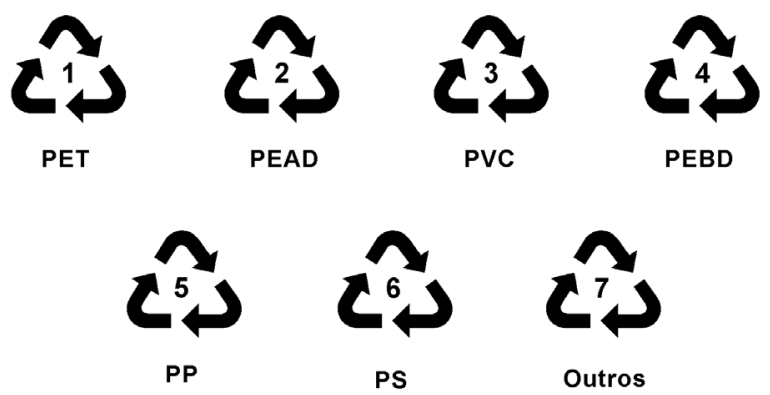

PET $=$ Poli(tereftalato de etileno), PEAD = Polietileno de alta densidade PVC = Poli(cloreto de vinila), PEBD = Polietileno de baixa densidade, $\mathrm{PP}=$ Polipropileno, $\mathrm{PS}=$ Poliestireno

Figura 2. Simbologia utilizada para identificação de embalagens poliméricas, Norma NBR 13.230 da ABNT (Associação Brasileira de Normas Técnicas)

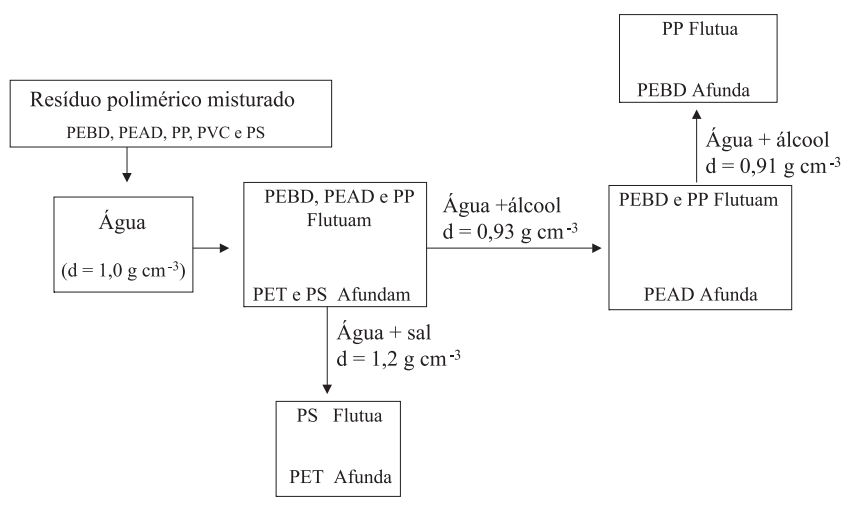

Figura 3. Esquema de separação de polímeros por diferenças de densidade

polímeros apresentam densidades próximas, este procedimento torna-se mais difícil ${ }^{39,40,43}$. O material metálico é retirado por separação eletrostática ${ }^{38,44-49}$.

Um exemplo da importância da etapa de separação é o caso do PET que sofre hidrólise, devido à presença de impurezas como o $\mathrm{PVC}, \mathrm{NaOH}$, detergentes alcalinos, adesivos como EVA, etc. A hidrólise do PET é um processo autocatalítico onde os grupos hidroxílicos terminais reagem formando grupos carboxílicos que aceleram a hidrólise, resultando em pontos pretos no produto transparente. A contaminação acima de 50 ppm de PVC torna o PET fora de especificação para a fabricação de filmes ${ }^{50}$. Algumas tecnologias alternativas têm sido desenvolvidas para detectar o cloro do PVC por fluorescência de raios-X, a fim de separá-lo previamente ${ }^{51}$.

Além destes métodos de separação de polímeros também são utilizados a espectroscopia Raman associada à análise multivariada ${ }^{52}$ ou espectroscopia na região do infravermelho próximo, que identificam polímeros transparentes ou coloridos ${ }^{53,54}$.

Apesar de se ressaltar a importância da etapa de separação, também é possível reciclar uma mistura de polímeros. Nos anos 70, foram desenvolvidos processos para a reciclagem de resíduos poliméricos misturados que admitem de 30 a $40 \% \mathrm{~m} / \mathrm{m}$ de contaminação por polímero não fundido (polímero com alta temperatura de fusão) e outros tipos de materiais, como papel, madeira, vidro ou metal; os outros $60 \% \mathrm{~m} / \mathrm{m}$ são constituídos de poliolefinas que possuem baixa temperatura de fusão e acabam encapsulando os contaminantes durante o processamento ${ }^{55-62}$.

Duas tecnologias, uma japonesa e outra Belga (Syntal) desenvolveram a chamada "madeira plástica". Neste tipo de processo pode- se utilizar uma mistura de PEBD, PEAD, poli(acrilonitrila- $c o$ butadieno-co-esireno) (ABS), PP e até $20 \% \mathrm{~m} / \mathrm{m}$ de PVC, sem problemas de liberação de gases tóxicos. O PS e as poliamidas são aceitáveis até $10 \% \mathrm{~m} / \mathrm{m}$ e o PET deve ser usado numa proporção máxima de $5 \% \mathrm{~m} / \mathrm{m}$ para não prejudicar a resistência e o acabamento dos perfis. A madeira plástica pode ser utilizada e trabalhada como a madeira comum ${ }^{63}$. A madeira plástica pode ser utilizada em mourões de cerca, cruzetas para sustentação de fios elétricos, pontaletes de construção civil, madeiras para bancos de praças, postes de sinalização de ruas e estradas, instalações para marinas e locais onde a corrosão seja elevada, pois estes objetos podem ficar expostos a intempéries sem sofrerem uma degradação muito rápida.

No Brasil também foram desenvolvidos produtos provenientes dos resíduos sólidos urbanos; o IMAWOOD ${ }^{\circledR}$ (constituído de mistura de poliolefinas provenientes de sacos e sacolas plásticas, principalmente PEBD e PEAD) e o IMACAR ${ }^{\circledR}$ (constituído de uma mistura de poliolefinas com predominância de PP e baixo teor de EPDM provenientes de pára-choques descartados), cujas marcas foram registradas pelo Instituto de Macromoléculas ${ }^{64}$.

Depois da separação, os resíduos poliméricos devem ser moídos em moinhos de facas rotativas e peneirados na forma aproximada de "pellets" antes do reprocessamento. Isto permite acomodar melhor o material no equipamento de processamento, como a extrusora ${ }^{38}$ ou a injetora. É importante que o material moído tenha dimensões uniformes para que a fusão também ocorra uniformemente. A presença de pó proveniente da moagem é inconveniente, pois este funde antes e atrapalha o escoamento do material nos equipamentos de processo.

O polímero depois de moído é lavado normalmente em tanques contendo água ou solução de detergente aquecido ${ }^{30}$. Nesta etapa é necessária a remoção de resíduos de detergente. A água de lavagem é tratada e reutilizada no processo ${ }^{65}$. A secagem do material é importante, pois alguns polímeros, como os poliésteres ou as poliamidas, podem sofrer hidrólise durante o reprocessamento. O resíduo de detergente pode agir como catalisador na hidrólise. O máximo de umidade residual tolerável para as poliolefinas é de cerca de $1 \% \mathrm{~m} / \mathrm{m}$ e para os poliésteres ou as poliamidas deve ser inferior a $0,02 \% \mathrm{~m} / \mathrm{m}^{66}$. A secagem pode ser feita por processo mecânico e/ou térmico.

Após a secagem, os polímeros são formulados, ou seja, são colocados aditivos como antioxidantes, plastificantes, cargas de reforço, agentes de acoplamento, etc., dependendo da aplicação final ${ }^{67-71}$. A quantidade e o tipo de antioxidantes e plastificantes adicionados nos polímeros pós-consumo normalmente são os mesmos utilizados para os polímeros virgens. Como cargas de reforço podem ser utilizadas as cargas minerais, como carbonato de cálcio, argilas, sílicas, mica, talco, alumina e dióxido de titânio. As cargas não minerais incluem negro de fumo, esferas e fibras de vidro e vários materiais orgânicos, tais como fibras vegetais. A adição destas cargas de reforço é uma alternativa viável, podendo melhorar as propriedades dos polímeros reciclados e torná-los competitivos em relação aos polímeros virgens. Para melhorar a adesão entre a matriz polimérica e a carga de reforço utiliza-se um agente de acoplamento, o qual é uma molécula bifuncional que se liga quimicamente à superfície das duas fases. Uma forte ligação interfacial favorece a mistura destas fases, promovendo uma melhora nas propriedades de compósitos e blendas. Os agentes de acoplamento mais utilizados são organosilanos, organotitanatos e polímeros funcionalizados (especialmente funcionalizações ácidas) $)^{72-74}$. Os agentes de acoplamento são adequados para a reciclagem de laminados multicamadas como PE/PA e PE/PET ${ }^{70}$.

Os aditivos à base de alcóxidos de titanatos ou zirconatos têm sido usados em concentrações da ordem de $0,2 \% \mathrm{~m} / \mathrm{m}$, visando promover a copolimerização ou a compatibilização in -situ de polímeros, como PELBD (polietileno de baixa densidade linear), policarbonato (PC), 
PET e PP e ainda atuaram como pigmento. A utilização destes aditivos promoveu uma melhora nas propriedades mecânicas dos produtos, diminuição da temperatura e dos ciclos de processamento ${ }^{75-78}$.

Também é possível formular os polímeros pós-consumo adicionando pequenas quantidades de material virgem, visando melhorar as propriedades dos polímeros reciclados. As poliolefinas possuem uma estrutura química mais estável comparada aos poliésteres e poliamidas, portanto, são menos reativas e sofrem pouca degradação durante o processamento. Conseqüentemente, para estes materiais a adição de pequenas quantidades de polímeros virgens pode levar a um efeito sinergístico. Já no caso dos poliésteres e poliamidas nem sempre isto ocorre, pois como eles são mais reativos normalmente degradam com maior facilidade durante o processamento. Neste caso, a mistura do material virgem e pós-consumo pode levar à uma separação de fases e, conseqüentemente, a um decréscimo das propriedades mecânicas ${ }^{68,70,79}$.

Após a formulação, o polímero pode ser reprocessado e finalmente obtido um novo artefato.

O processo de extrusão pode ser utilizado para se obter um produto acabado, como por ex. um perfil, ou em conjunto com outros processos como a injeção, a termoformagem etc. Não é conveniente utilizar apenas o processo de injeção ou a termoformagem, pois os produtos obtidos não apresentam uma homogeneidade adequada, influenciando no seu desempenho final. Quando, por ex., os polímeros pósconsumo apresentam uma variedade de cores também é importante fazer a homogeneização prévia (normalmente por extrusão) para depois processar por injeção ou termoformagem. Devido a isto, o processo de extrusão é muito utilizado para a reciclagem de polímeros. $\mathrm{O}$ polímero reciclado normalmente é heterogêneo, acarretando em variação das propriedades mecânicas do produto acabado. Esta heterogeneidade está relacionada à degradação que os polímeros sofrem durante as etapas do processo (moagem, lavagem, secagem, extrusão, etc) acarretando em degradação por cisalhamento, termo-oxidativa e por hidrólise. As poliolefinas sofrem principalmente degradação termo-oxidativa e por cisalhamento, podendo resultar em cisão de cadeia e/ou reticulação, levando à diminuição ou aumento da massa molar, respectivamente. Os poliésteres, as poliamidas e as poliuretanas são mais susceptíveis à hidrólise resultando na redução da massa molar. Em todos os casos ocorre um aumento da polidispersidade do tamanho das cadeias, afetando algumas propriedades como aparência, resistência química e características mecânicas.

Alguns trabalhos sobre reciclagem mecânica por extrusão convencional mostraram que existe um limite no qual as propriedades dos polímeros são mantidas, por exemplo, no caso do PET após três ciclos de processamento ocorre uma variação drástica nas propriedades mecânicas tornando-o duro e quebradiço e, portanto, não é possível utilizá-lo para as mesmas aplicações do polímero virgem ${ }^{68,80}$. Outros trabalhos mostraram que é possível reprocessar o PP mais de dez vezes, sem que ocorra alteração significativa nas propriedades mecânicas, o que é desejável do ponto de vista industrial ${ }^{79,81}$.

Para minimizar este problema é importante eliminar a maior quantidade possível de resíduos e de umidade ${ }^{82}$; além disso, no caso do processamento por extrusão é importante a utilização de um desenho específico de rosca, por ex. com barreiras, a qual promove uma plastificação do polímero reciclado de forma mais eficiente que as roscas convencionais, reduzindo assim a degradação dos polímeros durante o processamento ${ }^{83}$. A Figura 4 mostra os desenhos de rosca convencional e com barreiras usadas no processo de extrusão.

A caracterização "on-line" é outro recurso de baixo custo que pode ser usado para garantir a qualidade dos produtos obtidos com polímeros reciclados. Conhecer as propriedades dos polímeros durante o processo de transformação é um conceito promissor, que torna confiável o uso de polímeros reciclados. Já foi testado um sistema a)

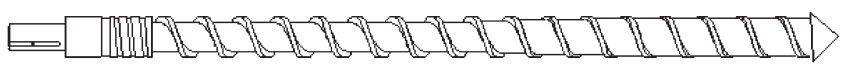

b)

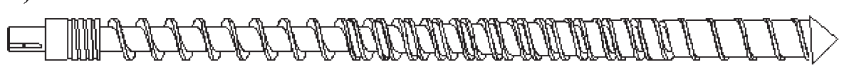

Figura 4. Desenho de roscas usadas no processo de extrusão: a) convencional e b) com barreira

"on-line" onde foram avaliadas a cor e a tenacidade do polímero, permitindo a rejeição de lotes fora de especificação. A determinação de outros parâmetros "on-line" como a composição química e o módulo de Young também estão sendo estudados ${ }^{84}$.

Existe uma grande preocupação com a reciclagem do PVC, devido à possibilidade da liberação de $\mathrm{HCl}$ durante o reprocessamento; no entanto, ele pode ser reciclado mecanicamente e deve ser cuidadosamente separado dos outros polímeros ${ }^{85}$. Recentemente, foi desenvolvido pela Solvay/SolVin um processo em larga escala chamado Vinylloop ${ }^{\circledR}$ para separar o PVC de outros polímeros através de dissolução seletiva sob pressão em metil-etil-cetona. Neste processo obtém-se o PVC limpo, que pode ser usado em novas formulações ${ }^{86,87}$.

O polímero reciclado é utilizado para fabricação de novos artefatos, normalmente diferentes dos que deram origem ao resíduo.

É crescente o número de trabalhos na literatura sobre a reciclagem mecânica dos termoplásticos encontrados nos resíduos sólidos urbanos reportando estudos sobre os processos e as propriedades dos polímeros reciclados $22,50,79-82,88-100$.

Apesar de apenas os termoplásticos serem considerados recicláveis por métodos mecânicos, também é possível a reciclagem de termofixos e elastômeros. Os termofixos podem ser usados como carga de reforço, ou incorporados para confecção de outros termofixos ${ }^{101,102}$. Os elastômeros reticulados podem ser incorporados na matriz de elastômero virgem ou pós-consumo ${ }^{103,104}$, desvulcanizados e misturados com termoplásticos ${ }^{105}$, ou no caso específico de luvas de látex, podem ser descontaminadas, processadas por "mastigação" e misturadas em cilindros, sendo produzida uma manta que posteriormente pode ser utilizada como matéria-prima para as mesmas aplicações da borracha natural ${ }^{106}$.

\section{Reciclagem química}

A reciclagem química ocorre através de processos de despolimerização por solvólise (hidrólise, alcoólise, amilose), ou por métodos térmicos (pirólise à baixa e alta temperaturas, gaseificação, hidrogenação) ou ainda métodos térmicos/catalíticos (pirólise e a utilização de catalisadores seletivos).

Os processos de despolimerização por hidrólise e glicólise de polímeros foram patenteados nos anos 60 e $70^{38}$. De modo geral, a solvólise é utilizada para polímeros como os poliésteres, as poliamidas e as poliuretanas ${ }^{107}$. Já os métodos térmicos e/ou catalíticos são mais utilizados para poliolefinas. A reciclagem química é muito utilizada pela indústria na Europa e no Japão, enquanto que no Brasil ela ainda está em desenvolvimento. A hidrólise conduz à recuperação dos monômeros de partida através de uma reação com excesso de água à alta temperatura na presença de um catalisador. Por exemplo, através da reação de hidrólise do PET é possível obter os produtos de partida que são o etileno glicol e o ácido tereftálico. Estes podem ser utilizados para obtenção do polímero novamente ${ }^{38,108}$.

O processo de hidrólise é utilizado pela United Resource Recovery Corporation que construiu uma planta para recuperar re- 
jeito de PET com $40 \% \mathrm{~m} / \mathrm{m}$ de impurezas ${ }^{109}$. Usando $\mathrm{NaOH}$ como catalisador obteve-se como produto o tereftalato disódico e o etileno glicol. O etileno glicol é recuperado por destilação a $200-350{ }^{\circ} \mathrm{C}$.

$\mathrm{Na}$ alcoólise ou especificamente na metanólise, o material é tratado com excesso de metanol. Em um típico processo de metanólise ${ }^{38}$ o PET fundido é misturado com metanol na presença de um catalisador ácido ou básico, aquecendo-se a mistura entre 160 e $240{ }^{\circ} \mathrm{C}$ por $1 \mathrm{~h}$, a pressão de 2,03 a 7,09 MPa. A tolerância de impurezas deste método é inferior a $10 \% \mathrm{~m} / \mathrm{m}$, o que é uma vantagem comparada a outros métodos como o reprocessamento, onde o limite é inferior a $1 \% \mathrm{~m} / \mathrm{m}$. Também é possível a despolimerização do PET até a obtenção dos monômeros, utilizando o metanol no seu estado supercrítico ${ }^{110}$. O grau de despolimerização e a seletividade do tereftalato de dimetila aumentam com o aumento da razão metanol/ PET e com a temperatura e tempo da reação. A metanólise é utilizada em várias plantas piloto de recuperação como a da Eastman Chemical, da Du Pont e da Hoescht Celanese ${ }^{38}$.

A glicólise ocorre quando o polímero é tratado com excesso de glicol, através de uma reação de transesterificação. Por exemplo, a quebra da cadeia do PET com excesso de etileno glicol é realizada em atmosfera de nitrogênio a $4 \mathrm{MPa}$ de pressão e na presença de acetato de zinco como catalisador. O principal produto formado é o oligômero de tereftalato de bis-hidroxietila ${ }^{111}$. Outros exemplos são a despolimerização de poliuretanas (PU) e elastômeros ${ }^{112,113}$. A PU de resíduo de refrigeradores foi despolimerizada em atmosfera inerte, usando etileno glicol como solvente e acetato de potássio como catalisador. Após $2 \mathrm{~h}$ de reação usando $2 \% \mathrm{~m} / \mathrm{m}$ de catalisador foi obtido um rendimento de $87-95 \%$ de polióis ${ }^{112}$.

A pirólise à baixa temperatura é a degradação térmica na ausência de ar ou deficiência de oxigênio. Neste caso ocorre principalmente a despolimerização e formação de pequena quantidade de compostos aromáticos e gases leves, como o metano, obtendo-se líquidos de alta temperatura de ebulição, como ceras e materiais de partida para produção de poliolefinas. Na pirólise à alta temperatura ocorre a decomposição térmica na ausência de ar ou deficiência de oxigênio, obtendo-se óleos e gases que, posteriormente, serão purificados por métodos petroquímicos padrões. Em poucos casos é possível recuperar os monômeros como produto principal. A pirólise é uma reação endotérmica, portanto é necessária a adição de calor, que pode ser fornecido diretamente (oxigênio-ar) ou indiretamente (troca de calor). Os polímeros com altos teores de impurezas podem ser reciclados por pirólise. No entanto, obtém-se uma grande variedade de produtos de decomposição que são de difícil separação e, além disso, possuem um valor comercial menor que os produtos obtidos por hidrólise. A pirólise é um processo complicado, pois os polímeros possuem baixa condutividade térmica e a degradação das macromoléculas requer alta quantidade de energia. A pirólise de polímeros tem sido estudada em vasos de fundição, alto forno, autoclaves, tubos reatores, forno rotatório, reator de leito fluidizado, etc. ${ }^{114-119}$

No Japão, uma planta de pirólise de leito fluidizado opera com ar ou oxigênio como gás fluidizante no reator. A oxidação parcial gera parte da energia de fissão necessária e parte do produto é queimado. Os produtos oleosos são parcialmente oxidados e o conteúdo de sua energia é cerca de $10 \%$ menor que os hidrocarbonetos puros ${ }^{38}$.

No caso do PVC os produtos de pirólise consistem principalmente de $\mathrm{HCl}(56 \% \mathrm{~m} / \mathrm{m})$ e negro de fumo, enquanto que a composição de outros polímeros é similar à obtida para o $\mathrm{PE}$. $\mathrm{O} \mathrm{HCl}$ proveniente da decomposição do PVC pode ser neutralizado com óxido de cálcio, formando o cloreto de cálcio. Quando são formadas grandes quantidades de cloreto de cálcio pode ocorrer o entupimento do fluidizador. A partir de poliésteres, poliamidas, poliuretanas e materiais contendo celulose são formados o dióxido e o monóxido de carbono $^{38}$.
Os óleos obtidos da pirólise de resíduos poliméricos contêm entre 50-200 ppm de compostos organoclorados. No entanto, não foi detectada a presença de dibenzodioxinas cloradas (altamente tóxicas) nestes compostos, o que foi confirmado por numerosas análises. A quantidade de cloro não deve exceder 10 ppm para que estes compostos sejam utilizados nas plantas petroquímicas ${ }^{120}$. Portanto, é adicionado vapor de sódio no fluxo de gás de pirólise para minimizar a quantidade de halogênios no óleo obtido ${ }^{121}$.

A degradação térmica de polímeros pode também ser realizada na presença de catalisadores, como as zeólitas ${ }^{122-126}$, visando aumentar o grau de conversão e a seletividade dos produtos obtidos ${ }^{127-130}$.

A vantagem da pirólise em relação à combustão é a redução de 5 a 20 vezes no volume do produto gasoso, conduzindo a uma considerável economia na purificação do gás obtido. Adicionalmente é possível obter hidrocarbonetos e, em alguns casos, produtos químicos brutos com alto valor comercial.

A gaseificação ${ }^{38}$ é um processo onde é inserido oxigênio insuficiente para que ocorra a combustão completa, ocorrendo simultaneamente a pirólise e a combustão no interior do leito. Neste processo que ocorre na presença de oxigênio e vapor d'água em temperaturas entre 1200 e $1500{ }^{\circ} \mathrm{C}$ são recuperados $\mathrm{CO}$ e $\mathrm{H}_{2}$ e pequenas quantidades de $\mathrm{CH}_{4}, \mathrm{CO}_{2}, \mathrm{H}_{2} \mathrm{O}$ e alguns gases inertes. Goulart e colaboradores $^{131}$ estudaram o processo de gaseificação de rejeitos de pneus em leito fluidizado e observaram que os subprodutos do processo possuem elevado potencial de utilização na indústria, tanto com insumos de processos produtivos (negro de fumo) como energético (voláteis e óleo obtido a partir da condensação dos vapores da gaseificação).

Na hidrogenação a quebra das cadeias poliméricas é inicialmente feita termicamente, resultando em radicais livres altamente reativos, os quais são posteriormente saturados com hidrogênio, obtendo-se hidrocarbonetos leves como metano, etano, propano e mistura de hidrocarbonetos na faixa de gasolina e diese ${ }^{38}$. A hidrogenação ocorre em temperaturas entre 440 a $480{ }^{\circ} \mathrm{C}$ e pressão de 15 a $25 \mathrm{GPa}$. A hidrogenação também é utilizada para reciclar resina epóxi reticulada com anidrido ftálico, usando tetralina e 9,10-diidroantraceno na temperatura de $340{ }^{\circ} \mathrm{C}$ por $2 \mathrm{~h}$, recuperando cerca de $99 \%$ de produtos como fenol, $p$-isopropilfenol e anidrido ftálico. A hidrogenação também pode ser usada para reciclar resina fenólica, resinas melanínicas e poliéster insaturado ${ }^{132}$

Os métodos de despolimerização permitem obter os monômeros de partida, que podem ser purificados por métodos convencionais e re-polimerizados, formando polímeros virgens.

\section{Reciclagem energética}

Se o reuso do resíduo polimérico não é prático ou econômico, é possível fazer uso de seu conteúdo energético através da incineração. No Japão, os resíduos sólidos urbanos são pré-separados em materiais combustíveis e não combustíveis para serem incinerados. Neste país em 1993, cerca de 50\% dos resíduos sólidos urbanos contendo $67 \%$ de resíduos poliméricos foram incinerados em dois mil incineradores municipais ${ }^{32}$. O conteúdo de energia dos polímeros é alto e muito maior que de outros materiais. O valor calórico de $1 \mathrm{~kg}$ de resíduo polimérico é comparável ao de $1 \mathrm{~L}$ de óleo combustível e maior que o do carvão. Os resíduos poliméricos contidos no resíduo sólido urbano contribuem com $30 \%$ deste valor calórico, permitindo a produção de eletricidade, vapor ou calor ${ }^{31}$.

Os polímeros que contenham halogênios (cloro ou flúor) em suas cadeias podem causar problemas durante a combustão devido à liberação de $\mathrm{HCl}$ ou $\mathrm{HF}$, podendo também ser uma fonte de emissão de dioxinas ${ }^{133}$. Atualmente é utilizado gás de lavagem reduzindo a emissão de $\mathrm{HCl}$ aos limites legais. Os polímeros contendo nitrogênio em 
sua estrutura liberam $\mathrm{NO}_{x}$. Além disso, na combustão pode ocorrer a liberação de metais, compostos orgânicos provenientes de tintas, pigmentos, cargas ou estabilizantes presentes nos polímeros ${ }^{31}$.

\section{ASPECTOS ECONÔMICOS, SOCIAIS E AMBIENTAIS RELACIONADOS À RECICLAGEM DE POLÍMEROS}

Os polímeros são considerados os grandes vilões ambientais, pois podem demorar séculos para se degradar e ocupam grande parte do volume dos aterros sanitários, interferindo de forma negativa nos processos de compostagem e de estabilização biológica. Além disto, os resíduos poliméricos quando descartados em lugares inadequados, como lixões, rios, encostas, etc., causam um impacto ainda maior ao meio ambiente. Portanto, a reciclagem de forma sistemática é uma das soluções mais viáveis para minimizar o impacto causado pelos polímeros ao meio ambiente. Vários aspectos motivam a reciclagem dos resíduos poliméricos contidos nos resíduos sólidos urbanos, a economia de energia, a preservação de fontes esgotáveis de matériaprima, a redução de custos com disposição final do resíduo, a economia com a recuperação de áreas impactadas pelo mau acondicionamento dos resíduos, o aumento da vida útil dos aterros sanitários, a redução de gastos com a limpeza e a saúde pública e a geração de emprego e renda.

Para se garantir o sucesso da reciclagem de polímeros são necessárias quatro condições básicas: 1) contínuo fornecimento de material bruto para uma organização adequada de coleta, separação e esquemas de pré-tratamento, 2) tecnologia de conversão adequada, 3) mercado para o produto reciclado e 4) viabilidade econômica ${ }^{133}$. No entanto, o abastecimento de materiais recicláveis tem crescido muito mais rápido que a capacidade de convertê-los em produtos usáveis e o preço destes materiais tem flutuado bastante, tornando difícil o planejamento de um sistema completo ${ }^{134}$.

Do ponto de vista econômico a reciclagem de polímeros não é considerada uma atividade com alto retorno financeiro, principalmente devido ao custo da coleta seletiva, que pode ser até cerca de oito vezes maior que a convencional ${ }^{19}$. Além disto, no Brasil, o resíduo polimérico pós-consumo é taxado em $15 \%$ de IPI para o PET e $5 \%$ para os demais polímeros, segundo decreto 4.544 e tabela do IPI (decreto 4.542), ambos de 26/12/2002 ${ }^{8}$. A redução na tributação irá incentivar a atividade de reciclagem, criando mais empregos e gerando riquezas.

Apesar destes fatores influenciarem os aspectos econômicos, o setor de reciclagem movimenta US\$ 160 bilhões/ano, com a comercialização de 600 milhões de $\mathrm{t}$ de produtos e emprega 1,5 milhão de pessoas, e foi estimado que este setor investe cerca de US\$20 bilhões/ano e que $1 / 3$ do comércio em volume é internacional ${ }^{135}$. Conseqüentemente, a reciclagem de materiais é uma perspectiva de negócio que vem sendo disseminada pelo meio empresarial e governamental, devido à possibilidade de sua efetiva implementação. Para isto é necessário que toda tecnologia, conceitos e capacidade empresarial sejam disponibilizados em busca de tornar um objetivo ecologicamente correto, em uma realidade economicamente viável. É importante ressaltar que os produtos reciclados obtidos por reciclagem mecânica sempre competirão com os produtos do mercado de "commodities" sob as variações cíclicas de preços. Atualmente, é quase impossível gerir uma empresa de reciclagem mecânica de médio porte que possui uma estrutura gerencial clássica. Devido a isso ocorreu o fechamento de várias empresas desse tipo nos EUA, em especial na área de PET. Conseqüentemente, apenas as empresas de grande porte e com modelos administrativos menos complexos resistiram no mercado. Outra condição importante é a necessidade de contratos de fornecimento do resíduo polimérico com municípios ou prestadores de serviço de coleta, em cidades que possuam programas de coleta seletiva. Ainda é necessário avaliar a quantidade, ou o volume do resíduo polimérico, assim como o tipo de contaminação presente, para se definir qual tipo de reciclagem é a mais adequada ecológica e economicamente ${ }^{8}$.

É crescente o interesse na reciclagem do PET, entretanto, as embalagens de PET recicladas não rendem muito aos recicladores e muitas empresas já faliram também aqui no Brasil, pois a maioria dos interessados em reciclar quer iniciar pelo PET. Este interesse pelas embalagens de PET vem da sua visibilidade nas calçadas, nos lixões, aterros e rios. Aparentemente disponíveis, as embalagens de PET têm como principal destino o lixão. Outros polímeros, como o PE, o PP e o PS têm demanda e oferta bem superior, além de necessitarem investimentos menores. A coleta seletiva é importante para a solução deste problema e sem ela, a reciclagem vai continuar deficiente ${ }^{8}$.

Através de entrevistas nos EUA, foi constatado que o consumidor se mostra interessado em reciclar e até apóia iniciativas nesta área. Na prática, porém ele não quer pagar mais pelos produtos reciclados. Foi verificado também que, tanto o consumidor quanto o fabricante, estão dispostos a pagar um pouco mais (de 10 a 15\%) por embalagens "ecologicamente responsáveis", mas este preço adicional ainda é insuficiente ${ }^{136}$. Algumas medidas já foram tomadas, tanto por parte dos fornecedores de material como dos fabricantes, para diminuição da quantidade de material (paredes mais finas, redução de tamanho) que resultaram em benefícios financeiros ${ }^{136}$.

Outro aspecto que vem sendo bastante discutido é a avaliação do ciclo de vida. Esta é feita a partir da definição técnica do processo envolvido para transformar matérias-primas e produtos. Nas diferentes unidades dessa cadeia de produção e consumo são levantados dados quantitativos sobre aspectos ambientais importantes, tais como emissões, consumo de recursos, consumo de energia e geração de resíduos. Uma característica marcante da avaliação do ciclo de vida é o fato de ser a única ferramenta de gestão ambiental aplicada do berço ao túmulo dos sistemas de produção. Ela permite identificar os aspectos ambientais em todos os elos da cadeia produtiva e consumo, desde a exploração das matérias-primas brutas até o uso final, passando pelo transporte, embalagem, reciclagem e destino final dos resíduos. No mercado existem casos clássicos sobre ciclo de vida de produtos. Os mais visíveis, provavelmente, são aplicados a embalagens ${ }^{137}$.

Um estudo detalhado e comparativo de avaliação integrada de ciclo de vida para produtos feitos com PVC e outros materiais foi realizado em 1994 por Jardim e Figueiredo ${ }^{138}$. Neste trabalho foram realizadas análises comparativas entre tubo de PVC e materiais como manilha de barro, tubo de cimento, ferro fundido e aço galvanizado. Também foram comparados os frascos de PVC com frascos de vidro para maionese; embalagens de folha de flandres e PVC para óleo de soja comestível; esquadrias de alumínio e de madeira com esquadrias de PVC e folhas "blister" de PVC com papel cartão. Este trabalho é um dos pioneiros no Brasil em destacar a importância da análise de ciclo de vida de produtos. No entanto, é necessária uma avaliação atualizada considerando o descarte e/ou a reciclagem deste material no Brasil.

Em 2001 foi realizado um estudo sobre a reciclagem de embalagens de PET no Brasil, segundo a metodologia da análise de ciclo de vida $^{139}$. Concluiu-se que quanto maior o índice de reciclagem maior é a redução dos resíduos sólidos, dos níveis de emissão para o ar e a água e do consumo de energia, água, petróleo e gás natural. Também foi realizado um estudo de análise de ciclo de vida de embalagens recicladas de PET e PE na Itália em 2001. Os resultados mostraram que para a produção de $1 \mathrm{~kg}$ de "flakes" de PET reciclado são consumidos 42-55 MJ de energia, enquanto que para o polímero virgem são necessários mais que $77 \mathrm{MJ}$. No caso do PE para o polímero reciclado são necessários 40-49 MJ e para o polímero virgem, cerca de 80 MJ de energia. Para estes cálculos assumiu-se que para o uso final não importava se o polímero era virgem ou reciclado ${ }^{140}$. 


\section{CONCLUSÕES}

A reciclagem de polímeros é uma alternativa viável para minimizar o impacto ambiental causado pela disposição destes materiais em aterros sanitários. Este tema vem se tornando cada vez mais importante pois, além dos interesses ambientais e econômicos, começam a surgir legislações cada vez mais rígidas no sentido de minimizar e/ou disciplinar o descarte dos resíduos sólidos.

A reciclagem mecânica é a mais utilizada no Brasil devido a vários fatores como custo de mão-de-obra, baixo investimento para instalação de uma planta de reciclagem, grande volume de polímero pós-consumo, etc., ao contrário dos países da Europa e do Japão que utilizam as reciclagens química e energética, majoritariamente. No Brasil, a reciclagem mecânica vem crescendo em volume e aumentando a diversidade e qualidade dos produtos, devido à otimização dos processos. É importante ressaltar que a reciclagem de polímeros, bem como o método de reciclagem a ser empregado, depende de vários fatores, como a quantidade e a qualidade do material, o custo do material e do processamento e a existência de mercado para o produto final. Assim, a coleta seletiva dos resíduos sólidos facilitaria a separação prévia dos polímeros, diminuiria o custo e aumentaria a eficiência da reciclagem. Além disso, o investimento em pesquisas na área de reciclagem de polímeros, como por exemplo, o desenvolvimento de metodologias que permitam realizar a análise de contaminantes de forma mais rápida, é de fundamental importância para obtenção de produtos de melhor qualidade.

\section{AGRADECIMENTOS}

Os autores agradecem ao PRONEx/CNPq e à FAPESP.

\section{REFERÊNCIAS}

1. Mano, E. B.; Mendes, L. C; Introdução a polímeros, 2aed., Edgard Blücher Ltda: São Paulo, 1999.

2. Elias, H. G.; An introduction to polymer science, $1^{\text {a }}$ ed., Verlog Chemie: Weinheim, 1997.

3. Wan, E.; Galembeck, E.; Galembeck, F.; Cadernos Temáticos de Química Nova na Escola 2002, n 2, 05.

4. Agnelli, J. A. M; Polímeros: Ciênc. Tecnol. 1996, 4, 9.

5. D’Almeida, M. L. O.; Vilhena A.; Lixo municipal: manual de gerenciamento integrado, $2^{\mathrm{a}}$ ed., IPT/CEMPRE: São Paulo, 2000.

6. http://www.plasticoonline.com.br/revista/pm319/commodities/ Injecao_e_extrusao.htm, acessada em Setembro 2003.

7. http://www.plasticoonline.com.br/revista/pm319/commodities/ importacao_alta.htm, acessada em Setembro 2003.

8. http://www.plastico.com.br/revista/pm342/reciclagem1.htm, acessada em Setembro 2003.

9. http://www.plasticoonline.com.br/revista/pm319/commodities/ consumo_cresceu.htm, acessada em Setembro 2003.

10. http://www.datamark.com.br/index2.html, acessada em Julho 2001.

11. Rick, U.; Jenny, T.; Ruster, U.; Plástico Industrial 2002, 46, 26.

12. Almeida, M. F. M.; Paixão, M.; Resumos do XXVI Congresso Iberoamericano de Engenharia Ecológica e ambiental, Lima, Peru, 1998.

13. Aguiar, A.; Philippi, A. Jr.; Resumos do XXVI Congresso Ibero-americano de Engenharia Ecológica e ambiental, Lima, Peru, 1998.

14. Pereira, R. C. C.; Machado, A. H.; Silva, G. G.; Quím. Nova na Escola 2002, $n^{\circ} 15,3$

15. http://www.datamark.com.br/Apresentacao/abieffinal/ ABIEFFinal_fullscreen.htm, acessada em Setembro 2003.

16. Kishimoto, A; Oka, T.; Yoshida, K.; Nakanishi, J.; Environ. Sci. Technol. 2001, 35, 2861.

17. Furtado, M. R.; Plástico Moderno 1996, junho, 8 .

18. http://www.plasticoonline.com.br/revista/pm323/plastivida.htm, acessada em Setembro 2003

19. http://www.cempre.org.br, acessada em Setembro 2001

20. Forlin, F.; Faria, J.; Polímeros: Ciênc. Tecnol. 2002, 12, 1.

21. http://www.cfsan.fda.gov/ dms/opa-cg3b.html, acessada em Setembro 2003

22. Franz, R.; Welle, F.; Food Addit. Contam. 2002, 19, 502.
23. Santos, A. S. F.; Manrich, S.; Resumos do 6o Congresso Brasileiro de Polímeros, Gramado, Brasil, 2001.

24. Resumos do Seminário Internacional Reciclagem de PET pós-consumo para contato com alimentos, Campinas, Brasil, 2003.

25. Ferro, S.; Plástico Moderno 1999, maio, 8.

26. Brandrup, J.; Makromol. Chem.; Macromol. Symp. 1992, 57, 57.

27. Thorhein, H. R.; Armstrong, D. J.; Chemtech 1992, 23, 55.

28. http://www.abipet.com.br, acessada em Setembro 2003.

29. Sammarco, C.; Delfini, L.; Plástico Industrial 1999, 7, 106.

30. Ehrig, R. J.; Curry, M. J. Em Plastics recycling: products and processes; Ehrig, R. J., ed.; Oxford University Press: New York, 1992.

31. Kaminsky, W.; Ullmann's Encyclopedia of industrial Chemistry, VHC Verlags Publishes Inc, A 21, 1992, cap. 2.

32. Nir, M. M.; Miltz, J.; Ram, A.; Plast. Eng. 1993, 49, 75.

33. Ferro, S.; Plástico Moderno 1999, 304, 16

34. Sandani, G.; Chem. Eng. 1995, 102, 15.

35. Norma NBR 13.230 da ABNT (Associação Brasileira de Normas Técnicas).

36. Vilhena, A.; Guia de coleta seletiva de lixo, $1^{\text {a }}$ ed., CEMPRE: Compromisso Empresarial para Reciclagem ed.: São Paulo 1999, p. 26.

37. Braun, D.; Simple methods for identification of plastics, Macmillan Publishing Co., Hanser Publishers: New York, 1982.

38. Brandrup, J.; Bittner, M.; Michaeli, W.; Menges, G. Em Recycling and recovery of plastics; Willenberg, B., ed.; Hanser Publishers ed.: Munich, 1996.

39. Marques, G. A.; Tenório, J. A. S.; Waste Management 2000, 20, 265.

40. Pascoe, R. D.; O'Connell, B.; Waste Management 2003, 23, 845.

41. Shen, H. T.; Pugh, R. J.; Forssberg, E.; Colloids Surf., A 2002, 196, 63.

42. Besendorfer, C.; Chem. Eng. 1996, sep., 108.

43. Pascoe, R. D.; O’Connell, B.; Miner. Eng. 2003, 16, 1205.

44. Iuga, A.; Morar, R.; Samuila, A.; Descalescu, L.; IEEE Proc.-Sci. Meas. Technol. 2001, 148, 47.

45. Dascalescu, L.; Urs, A.; Dumitran, L. M.; Samuila, A.; IEEE Trans. Ind. Appl. 2003, 39, 362.

46. Rafiroiu, D.; Suarasan, I.; Morar, R.; Atten, P.; Dascalescu, L.; IEEE Trans. Ind. Appl. 2001, 37, 766.

47. Vlad, S.; Iuga, A.; Dascalescu, L.; IEEE Trans. Ind. Appl. 2003, 39, 66.

48. Dodbiba, G.; Shibayama, A.; Miyazaki, T.; Fujita, T.; Mater. Trans. 2003, $44,161$.

49. Inculet, I. I.; Castle, G. S. P.; Brown, J. D.; Part. Sci. Technol. 1998, 16, 91.

50. Pawlak, A.; Pluta, M.; Morawiec, J.; Galeski, A.; Pracella, M.; Eur. Polym. J. 2000, 36, 1875

51. Frish, A.; Razem, C.; Adv. Mater. 1995, 7, 513.

52. Allen, V.; Kalivas, J. H.; Rodrigues, E. G.; Appl. Spectrosc. 1999, 53, 672.

53. Inada, K.; Matsuda, R.; Fujiwara, C.; Nomura, M.; Tamon, T.; Nishihara, I.; Takao, T.; Fujita, T.; Resources Conservation \& Recycling 2001, 33, 131.

54. Garcia, D.; Borden, F.; Bouveresse, E.; J. Vinyl Addit. Technol. 2001, 7, 214.

55. Fang, Z. P.; Zeng, M. F.; Cai, G. P.; Xu, C. W.; J Appl. Polym. Sci. 2002, 82, 2947.

56. Xanthos, M.; Narth, K. A.; Polym. Compos. 1998, 19, 768.

57. Farahmand, F.; Shokrollahi, P.; Mehrabzadeh, M.; Iranian Polym. J. 2003, 12,185

58. Mehrabzadeh, M.; Farahmand, F.; J. Appl. Polym. Sci. 2001, 80, 2573.

59. Ha, C. S.; Park, H. D.; Cho, W. J.; J. Appl. Polym. Sci. 1999, 74, 1531.

60. Khait, K.; Torkelson, J. M.; Polym. Plast. Technol. Eng. 1999, 38, 445.

61. Kukaleva, N.; Simon, G. P.; Kosior, E.; Polym. Eng. Sci. 2003, 43, 26.

62. Klason, C.; Kubát, J.; Skov, H. R.; Resumos do International Recycling Congress, Genebra, Suiça, 1993.

63. Souza, W.; Plástico Moderno 1993, maio, 13.

64. Martins, A. F.; Suarez, J. C. M.; Mano, E. B.; Polímeros: Cienc. Tecnol. 1999, 9, 27.

65. Remédio, M. V. P.; Zanin, M.; Teixeira, B. A. N.; Polímeros: Ciênc. Tecnol. 1999, 9, 177

66. Al-AbdulRazzak, S.; Jabarin, S. A.; Polym. Int. 2002, 51, 164.

67. Silva Spinacé, M. A.; Pedroso, A. G.; De Paoli, M. A.; Br PI 201.054-2 2002.

68. Silva Spinacé, M. A.; Tese de Doutorado, Universidade Estadual de Campinas, Brasil, 2000.

69. La Mantia F. P.; Macromol. Symp. 2003, 194, 101

70. Pfaendner, R.; Plástico Industrial 2001, 37, 26.

71. Sahnoune, F.; Lopez Cuesta, J. M.; Crespy, A.; Polym. Eng. Sci. 2003, 43, 647.

72. http://www.specialchem4polymers.com/resources/articles/ printeartcle.aspx?id=1355, acessada em Novembro 2003.

73. DiBenedetto, A. T.; Mater. Sci. Eng., A 2001, 302, 74. 
74. Monte, S. J.; Sugerman, G. Em Adhesion aspects of polymeric coatings; Mittal, K. L., ed.; Plenum Press: New York, 1983.

75. Monte, S. J.; Polym. Polym. Compos. 2002, 10, 121.

76. Monte, S. J.; Plástico Industrial 2002, 44, 72.

77. Monte, S. J.; Cellular Polym. 2001, 20, 149.

78. Monte, S. J.; Polym. Polym. Compos. 2002, 10, 1.

79. Martins, M. H.; De Paoli, M A.; Polym. Degrad. Stab. 2002, 78, 491.

80. Silva Spinacé, M. A.; De Paoli, M. A.; J. Appl. Polym. Sci. 2001, 80, 20.

81. Mihut, C.; Captain, D. K.; Gadala-Maria, F.; Polym Eng Sci. 2001, 41, 1457

82. Santos, A. S. F.; Agnelli, J. A. M.; Manrich, S.; Polímeros: Ciênc. Tecnol. 1999, 9, 189.

83. Goerz, R.; Plástico Industrial 2001, 38, 64.

84. Schubert, T.; Ehrenstein, G. W.; Plástico Industrial 2001, outubro, 76.

85. Piva, A. M.; Bahiense Neto, M.; Wiebeck, H.; Polímeros: Ciênc. Tecnol. 1999, 9, 195.

86. Knauf, U.; Mäurer, A.; Holley, W.; Wiese, M.; Utschick, H.; Plástico Indústrial 2001, junho, 62

87. Yernaux, J. M.; Saffert, R.; Plástico Industrial 2003, 57, 52.

88. Canevarolo, S. V.; Polym. Degrad. Stab. 2000, 70, 71.

89. La Mantia, F. P.; Gardette, J. L.; Polym. Degrad. Stab. 2002, 75, 1.

90. Cruz, S. A.; Zanin, M.; Polym. Degrad. Stab. 2003, 80, 31.

91. Pawlak, A.; Morawiec, J.; Pazzagli, F.; Pracella, M.; Galeski, A.; J. Appl. Polym. Sci. 2002, 86, 1473.

92. Mansour, S. H.; Abd-el-Messieh, S. L.; Ikladious, N. E.; J. Appl. Polym. Sci. 2002, 85, 2501.

93. Rosa, D. S.; Guedes, C. G. F.; Polímeros: Ciênc. Tecnol. 2003, 13, 64.

94. Steffani, E.; Finkler, M.; Plástico Industrial 1999, 8, 40.

95. Santos, A. S. F.; Agnelli, J. A. M.; Trevisan, D. W.; Manrich, S.; Polym. Degrad. Stab. 2002, 77, 441.

96. Martins, M. H.; De Paoli, M. A.; Polym. Degrad. Stab. 2001, 71, 293.

97. Kartalis, C. N.; Papaspyrides, C. D.; Pfaendner, R.; Polym. Degrad. Stab. 2000, 70, 189.

98. Torres, N.; Robin, J. J.; Boutevin, B.; Eur. Polym. J. 2000, 36, 2075.

99. Pacheco, M. F.; Zattera, A. J.; Ferreira, C. A.; De Mori, P. R.; Zeni, M.; Freire, E.; Resumos do $2^{\text {nd }}$ International Symposium Feedstock Recycling of Plastics, \& Other Innovative Plastics Recycling Techniques, Ostend, Belgica, 2002.

100. Maspoch, M. L.; Ferrando, H. E.; Velasco, J. I.; Macromol. Symp. 2003, 194, 295.

101. Lewis, P. R.; Plástico Industrial 2001, 29, 60.

102. Pedroso, A. G.; Rosa, D. S.; Atvars, T. D. Z.; Progress in Rubber, Plastics and Recycling Technology 2002, 18, 111.

103. Jacob, C.; De, P. P.; Bhowmick, A. K.; De, S. K.; J. Appl. Polym. Sci. 2001, $82,3293$.

104. Silva Spinacé, M. A.; De Paoli, M. A.; Br PI 202.608-2 2002.

105. Scuracchio, C. H.; Isayev, A. I.; Bretãs, R. E. S.; Resumos do 6o Congresso Brasileiro de Polímeros, Gramado, Brasil, 2001.

106. Éspér, F. J.; Feijó, A. M.; Yoshiga, A.; Forini, S.; Wiebeck, H.; Resumos do $6^{o}$ Congresso Brasileiro de Polímeros, Gramado, Brasil, 2001.

107. Paszun, D.; Spychaj, T.; Ind. Eng. Chem. Res. 1997, 36, 1373.
108. Mancini, S. D.; Zanin, M.; Polímeros: Cienc. Tecnol. 2002, 12, 34. 109. Sandani, G.; Chem. Eng. 1995, 102, 15.

110. Yang, Y.; Lu, Y.; Xiang, H.; Xu, Y.; Li, Y.; Polym. Degrad. Stab. 2002, 75, 185

111. Kao, C. Y.; Cheng, W. H.; Wan, B. Z.; Thermochim. Acta 1997, $292,95$.

112. Wu, C-H.; Chang, C-Y.; Li, J-K.; Polym. Degrad. Stab. 2002, 75, 413.

113. Borda, J.; Pásztor, G.; Zsuga, M.; Polym. Degrad. Stab. 2000, 68, 419.

114. Bockhorn, H.; Hentschel, J.; Hornung, A.; Hornung, U.; Chem. Eng. Sci. 1999, 54, 3043

115. Mastellone, M. L.; Perugini, F.; Ponte, M.; Arena, U.; Polym. Degrad. Stab. 2002, 76, 479

116. Williams, P. T.; Williams, E. A.; J. Anal. Appl. Pyrolysis 1999, 51, 107.

117. Kamisky, W.; Schimidt, H.; Simon, C. M.; Macromol. Symp. 2000, 152, 191.

118. De Marco, I.; Caballero, B.; Torres, A.; Laresgoiti, M. F.; Chomon, M. J.; Cabrero, M. A.; J. Chem. Technol. Biotechnol. 2002, 77, 817

119. Kaminsky, W.; Eger, C.; J. Anal. Appl. Pyrolysis 2001, 58, 781.

120. Kaminsky, W.; J. Physique IV 1993, 3, 1543.

121. Winter, H.; Mostert, H. A. M.; Smeets, P. J. H. M.; Paas, G.; J. Appl. Polym. Sci. 1995, 57, 1409

122. Breck, D. W.; Zeolites molecular sieves: structure, chemistry and use, John Wiley \& Sons: New York, 1974.

123. Pujado, P. R.; Rabo, J. A.; Antosf, G. J.; Gembicki, S. A.; Catal. Today 1992, 13, 113

124. Davis, M. E.; Acc. Chem. Res. 1993, 26, 111.

125. Vansant, E. F.; J. Mol. Catal. A: Chem. 1997, 115, 379.

126. Thomas, J. M.; J. Mol. Catal. A: Chem. 1997, 115, 371.

127. Ali, S.; Garforth, A. A.; Harris, D. H.; Rawlence, D. J.; Uemichi, Y.; Catal. Today 2002, 75, 247.

128. Aguado, J.; Serrano, D. P.; Escola, J. M.; Garagorri, E.; Catal. Today 2002, $75,257$.

129. Park, J. W.; Kim, J-H.; Seo, G.; Polym. Degrad. Stab. 2002, 76, 495.

130. Chiu, S. J.; Cheng, W. H.; Polym. Degrad. Stab. 1999, 63, 407.

131. Goulart, E. A.; Mariotoni, C. A.; Sanchez, C. G.; Polímeros: Ciênc. Tecnol. 1999, 9, 123.

132. Braun, D.; Von Gentzkow, W.; Rudolf, A. P.; Polym. Degrad. Stab. 2002, 74,25 .

133. Mader, F. W.; Makromol. Chem., Macromol. Symp. 1992, 57, 15.

134. Hendricksin, C.; Lave, L.; McMichael, F.; Chemtech 1995, 25, 56.

135. http://www.plastico.com.br/revista/pm327/reciclagem4htm, acessada em Outubro 2002.

136. Baumann, M. H.; Plástico Industrial 1999, março, 98

137. http://www.ambienteglobal, acessada em Julho 2003.

138. Jardim, W. F.; Figueiredo, P. J. M.; Grassi, M. T.; Cunha, M.; Menna, D. T. G.; Estudo Comparativo entre alguns Produtos a base de PVC e outros materiais, Projeto ABIVINILA/UNICAMP/UNIMEP, 1984.

139. Garcia, E. E. C.; Coltro, L.; Resumos do $6^{\underline{a}}$ Congresso Brasileiro de Polímeros, Gramado, Brasil, 2001.

140. Arena, U.; Mastellone, M. L.; Perugini, F.; International Journal of Life Cycle Assessment 2003, 8, 92 . 